\title{
CLINICAL AND RADIOGRAPHIC EVALUATION OF HEALING EFFECT OF LOW LEVEL LASER THERAPY ON CHRONIC APICAL LESIONS
}

\author{
Latifa Mohamed Abdelgawad* and Laila Mohamed Kenawi**
}

\begin{abstract}
Objective: This study evaluated clinically and radiographically, the healing in chronic apical lesions using low level laser therapy (LLLT).

Methods: Twenty female patients between the ages of 20 and 30 years with chronic apical lesions in anterior maxillary teeth diagnosed on the basis of their clinical signs and symptoms and radiographic findings were included in the study. The patients were randomly divided into two main groups according to treatment plan: group I; received conventional endodontic treatment only, group II; received conventional endodontic treatment and then LLLT was used. The low level laser was applied for 120 seconds in the session for three sessions in week for four weeks and the selected parameters were $(200 \mathrm{mw}, 810 \mathrm{~nm}, \mathrm{CW})$. The healing was evaluated clinically, radiographically. Clinically to record pain, swelling, or any other adverse event that occur after treatment for one week. Radiographically to evaluate bone density and area of periapical lesions using cone beam computed tomography (CBCT) and image fusion. Images were obtained immediate after obturation and after the three follow up periods (1, 3 and 12 month) .
\end{abstract}

Results: clinical signs and symptoms decreased in the lased group faster than conventional group. Pain reduction in the laser group was more effective than the conventional group without significant difference. Bone density analysis showed that Laser had significantly higher bone density after 1,3 and 12 month evaluation periods compared to control group $(\mathrm{P}<0.05)$. Comparing the area values of control and laser groups, a significant difference was found throughout the three evaluation periods compared to the area immediate after obturation.

Conclusions: Based on the results of this study; LLLT favored the healing process of apical lesions especially when combined with nonsurgical endodontic treatment. Image fusion and CBCT can provide an accurate and reproducible method for assessment the healing of periapical lesions.

KEY WORDS: Low-level laser therapy; Bone healing, chronic apical lesions, cone beam computed tomography (CBCT)

\footnotetext{
* Associate Professor of Endodontics, Laser Insitute of Laser Enhanced Sciences(NILES), Cairo University, Cairo, Egypt.

** Lecturer of Endodontics, Faculty of Oral and Dental Medicine, Cairo University, Cairo, Egypt.
} 


\section{INTRODUCTION}

Periapical lesions of endodontic origin represent an inflammatory response to bacterial infection of the root canal. The bacterial infection generally result in total pulp necrosis accompanied by the development of an immune response in the periapical lesions that cause periapical bone destruction ${ }^{(1)}$.Bone resorption and loss of skeletal mass is the only function of osteoclasts ${ }^{(2)}$.Periapical radiolucency is the most pronounced clinical hallmark of these lesions. Most, but not all, periapical lesions will heal in response to properly performed endodontic treatment ${ }^{(3)}$.

The occurrence of chronic apical disease can remain unnoticed for prolonged periods of time or a patient in pain may seek dental care. Clinically, the existence of apical pathosis may be detected by sensitivity to biting or percussion, but asymptomatic apical periodontitis frequently does not elicit such a response ${ }^{(4)}$.

The scientifically documented procedure for the best results in canal disinfection of teeth with apical periodontitis is based on complete debridement and irrigation of the root canal during the first appointment ${ }^{(5)}$, followed by the application of calcium hydroxide [Ca $(\mathrm{OH}) 2]$ dressing $^{(6)}$ .Obturation of the root canal is then performed at the second or later appointment ${ }^{(7)}$.

It has been shown that treatment with $\mathrm{Ca}(\mathrm{OH}) 2$ as an intracanal dressing in the presence of periapical lesions can create environment more conductive to healing and start bone repair ${ }^{(8)} \cdot \mathrm{Ca}(\mathrm{OH}) 2$ is an effective intracanal antibacterial agent because of its high PH 12.5 with bactericidal and bacteriostatic effect ${ }^{(5-8)}$.

Conventional intraoral periapical radiography remains the standard for radiological diagnosis of existence, persistence or healing of apical periodontitis ${ }^{(9)}$. Digital radiography has become widespread since the 1980s; it reduced patient dose and eliminated development time ${ }^{(10)}$. Cone beam computed tomography (CBCT) has been introduced in the 1990s and has found a variety of indications in endodontics ${ }^{(11)}$. It has also been suggested to be superior in detecting periapical bone loss in situations where no pathosis was detected in periapical radiographs ${ }^{(12)} \mathrm{CBCT}$ can be used for more precise radiographic evaluation of periapical lesion areas measured in different followup periods, owing to the method's ability to detect extremely small bone changes ${ }^{(13-16)}$.

Low level laser therapy (LLLT) is the application of light usually a low power laser in the range of $1 \mathrm{mw}$ to $500 \mathrm{mw}{ }^{(17)}$ using wavelengths usually in the red and near-infrared spectrum (600-1000 nm), because other wavelengths are absorbed by melanin pigments in skin, hemoglobin in blood or water in tissues and do not reach the mitochondria of target tissues ${ }^{(18)}$. LLLT uses photonic energy to provide biological therapeutic advantages and is considered a noninvasive and painless process ${ }^{(19)}$. The biostimulatory and inhibitory effects of lasers are based on Arndt-Schultz Law, which indicates that weak stimuli will increase physiological processes and strong stimuli will inhibit physiological activity ${ }^{(20)}$.

Some studies indicate that LLLT stimulates cell proliferation ${ }^{(18)}$, osteoblast activity, vascularization, and collagen deposition ${ }^{(19)}$. During the initial stages of bone repair, LLLT increases the expression of osteogenic genes and stimulate new bone formation ${ }^{(20)}$.

Several studies have demonstrated that the nonsurgical near-infrared laser is more suitable for bone repair, due to deeper penetration in bone tissue when compared to visible laser ${ }^{(21)}$. Although the use of LLLT on bone healing biomodulation has been growing steadily and several studies have demonstrated positive results on the healing of bone tissue ${ }^{(18-21)}$. Few studies had attempted quantitative assessment of the effects of LLLT on periapical healing by CBCT. In this way, considering the 
above mentioned differences in the healing process of periapical lesions, along with the biomodulation activity of LLLT, the aim of the present study was to evaluate the effect of LLLT both clinically and radiographically on healing of periapical lesions.

\section{MATERIALS AND METHODS}

\section{Selection of the cases}

The clinical design and protocol of this study were approved by the research ethics committees of Oral and Dental Medicine, Cairo University (9/6/2014). All patients underwent endodontic treatment in the Endodontic Department, Faculty of Oral and Dental Medicine, Cairo University.

Twenty female patients with chronic apical periodontitis of maxillary anterior teeth were selected and their mean age was $25 \pm 2.99$ years (range 20 -30 years). These patients were seen over one year period, from August 2014 to August 2015. The patients were treated after they had been informed of the benefits of the planned procedures. All provided written informed consent to participate in this study.

All Selected patients were systemically healthy and not receiving any medication at the time of study. The inclusion criteria were as follows; accepted oral hygiene, no evidence of gingival inflammation, no evidence of acute oral infection.

\section{Endodontic procedure (treatment)}

Teeth were subjected to a common two- visit root canal treatment. In the first visit, access cavities, cleaning and shaping of root canals was done by a step back technique using hand files with intermittent irrigation with $2.5 \% \mathrm{NaOCl}$ (Clorox, Nobelwax Factories for chemicals, Egypt). $\mathrm{Ca}(\mathrm{OH})_{2}$ (Sigma chemicals, sigma-Aldrich cheme Gmbh, Germany) mixed with saline was placed as intra canal medicament. Access cavities restored with Glass ionomer (Medifil; Promedica; Neumuenster/ Germany) until the next visit. On the second visit, the tooth was checked for any symptoms such as pain, swelling, sensitivity to percussion, or which took place 7 days after the first visit, Patient recalled after a week for review. During the recall visit, after removing the Glass ionomer coronal filling, the root canals were irrigated by using $1 \mathrm{~mL} 15 \%$ EDTA (Endo-Solution, Cerkamed, Stalowa Wola, Polska). to remove the smear layer, and the root canals were filled with gutta-percha (Meta Biomed, Cheongju, Korea) and zinc oxide eugenol sealar (Dentsply DeTrey, Konstanz, Germany) by using a lateral compaction technique.

\section{Study design (Grouping of the cases)}

The selected twenty cases were randomly divided in two equal groups. The control group cases received conventional endodontic treatment only without low level laser irradiation. Laser group cases received low level laser irradiation after conventional endodontic treatment.

\section{Laser irradiation}

Irradiation schedule with a total of 12 sessions postobturation; started with immediate postobturation session, and then the following irradiation sessions were delivered to the patients as three session per week on a "day on day off" basis within four week. Infrared low power diode laser device locally manufactured (photon Scientific, Industrial area Qaliub, Egypt) was used in this study for irradiating the laser group. The laser device is $810 \mathrm{~nm}$ with output power of $200 \mathrm{~mW}$ (at the end of the intraoral tip), the total exposure time was 120 seconds. per tooth periapical lesion from labial side. The laser beam was a continuous wave $(\mathrm{C} \mathrm{W})$, and the laser delivery tip was used in contact mode.

\section{Evaluation of treatment}

Patients were clinically and radiographically were evaluated immediately after obturation. Clinical evaluation was done daily for one week and radiographic evaluation was done one, three and twelve month after obturation. 


\section{a) Clinical evaluation of the treatment}

The investigated teeth and surrounding tissues were clinically examined for any signs of inflammation, namely pain, swelling, tenderness to percussion or any other adverse event that occur after obturation for one week .

\section{Pain evaluation}

A visual analogue pain scale was given to each patient to record pain preoperatively. The patient's mark on the horizontal scale represented the intensity of pain experienced at the selected time according to the following criteria; (1) No pain: the treated tooth felt normal,(2) Slight pain: the tooth involved was slightly painful for a time, regardless of the duration, but there was no need to take analgesics, (3) Moderate pain: the tooth involved caused discomfort and/or pain, which was either tolerable or was rendered tolerable by analgesics,(4) Severe pain: the pain caused ,by the treated tooth disturbed normal activity or sleep and analgesics had little or no change in pain score after treatment ${ }^{(22)}$. Pain evaluation was done through studying the change in pain score after treatment and pain absence during follow up.

\section{b) Radiographic Evaluation}

\section{Digital Radiographic Evaluation}

Digital intraoral radiographs were taken with standardized paralleling technique by the XCP alignment system (Trophy Radiology, 94300 Vin Cennes, Type 6510, France) to obtain pre and postoperative radiographs for comparison for all patients.

\section{Cone beam}

CBCT images for the maxillary anterior region were obtained immediately after obturation, one, three and twelve month after endodontic treatment for five cases in each group. CBCT machine (Soredex, Helsinki, Finland) used in this study was characterized by the following: The detector of this machine is composed of CMOS flat panel with isotropic voxel size $133 \mathrm{Um}$. The X-ray tube used to scan the samples posses a current intensity 16 $\mathrm{mA}$, Kilovoltage $85 \mathrm{Kvp}$ and a focal spot size 0.5 $\mathrm{mm}$. The scanning time was 10 seconds (according to the FOV used) of pulsed exposure resulting in an effective exposure time 3 seconds to scan FOV of $6 \mathrm{~cm}$ Height x $6 \mathrm{~cm}$ Width x $6 \mathrm{~cm}$ Depth, FOV adjustment was guided by three laser light beams to centralize the area of interest within the scanning field. Image assessment was performed by a calibrated endodontist and a maxillofacial radiologist using the CBCT software tools Ondemand 3D (Cybermed Inc. Seoul, Korea). Assessment included evaluation of the extent or area of the lesion and bone density. All scan parameters were identical.

\section{Statistical analysis}

The collected radiographic data (bone density and area of periapical lesions) were presented as mean and standard deviation values to test the significance of difference during the three follow up periods (1, 3 and 12 month). Newman-Keuls Multiple Comparison Test was used to test the significance of difference during the three follow up periods between the two groups at the different follow up periods (one, three and twelve month). Results were considered statistically significant at $\mathrm{P}<0.05$. Pain data were analyzed by chi-square test.

\section{RESULT}

\section{Clinical assessment}

Results of clinical evaluation showed that the condition of 14 teeth was asymptomatic (70\%) and discovered during radiographic investigation in the other department while in the remaining 6 teeth (30\%) were painful. Three patients with painful teeth were included in control group and the other three patients were included in laser group.

For all patients, obturation was done in the 
second visit after one week from the first visit when the teeth were not painful and canals were dry. Clinical assessment was done daily for one week after treatment and laser application. All the cases became asymptomatic after one week in control and laser groups.

\section{Follow up of pain}

\section{Overall comparisons of the two groups}

In control group, the change in recorded pain scores during one week after treatment showed that, score 1 was recorded in $70 \%$ of the cases immediate after obturation, while it increased to $80 \%$ in the second day after obturation and $90 \%$ in the fourth day of obturation and $100 \%$ in the six day of obturation. Score 2 was recorded in $10 \%$ of the cases which disappear in forth day. Score 3 was recorded in $20 \%$ of the cases which changed to $10 \%$ in the fourth day after obturation and then disappear in the sixth day.
In laser group, the score 1 was recorded in $70 \%$ of the cases after the first laser session which changed to $100 \%$ after the third laser session. score 2 was recorded in $10 \%$ of the cases which disappear after the second laser session (second day). Score 3 was recorded in $20 \%$ of the cases which disappear after the third laser session ( fourth day) .There was no significant difference between the two groups.

\section{Radiographic assessment}

\section{A) Bone density:}

\section{Overall comparisons of two groups:}

\section{Table 2. Figure 1, 2, 3}

Regarding the bone density in control group; the bone density at 1,3 and 12 month was significantly higher than the bone density immediate after obturation $(\mathrm{P}<0.001)$. The twelve month bone density was significantly the best in control group $(\mathrm{P}<0.001)$.

TABLE (1): Comparison between the change in recorded pain scores between the control and lased group during one week follow up

\begin{tabular}{|c|c|c|c|c|c|c|}
\hline \multirow{3}{*}{ Group } & \multicolumn{6}{|c|}{ Pain score } \\
\hline & \multicolumn{2}{|c|}{ Score 1} & \multicolumn{2}{|c|}{ Score 2} & \multicolumn{2}{|c|}{ Score 3} \\
\hline & No & $\%$ & No & $\%$ & No & $\%$ \\
\hline \multicolumn{7}{|l|}{ Control } \\
\hline Immediate after obturation & 7 & $70 \%$ & 1 & $10 \%$ & 2 & $20 \%$ \\
\hline 2 nd day after obturation & 8 & $80 \%$ & 0 & $0 \%$ & 2 & 20 \\
\hline $4^{\text {th }}$ day after obturation & 9 & $90 \%$ & & & 1 & $10 \%$ \\
\hline $6^{\text {th }}$ day after obturation & 10 & $100 \%$ & 0 & $0 \%$ & 0 & $0 \%$ \\
\hline \multicolumn{7}{|l|}{ Laser } \\
\hline Immediate ( $1{ }^{\text {st }}$ laser session) & 7 & $70 \%$ & 1 & $10 \%$ & 2 & $20 \%$ \\
\hline $2^{\text {nd }}$ day ( $2^{\text {nd }}$ laser session & 9 & $90 \%$ & 0 & $0 \%$ & 1 & $10 \%$ \\
\hline $4^{\text {th }}$ day ( ${ }^{\text {rd }}$ laser session ) & 10 & $100 \%$ & 0 & $0 \%$ & 0 & $0 \%$ \\
\hline
\end{tabular}

Score $1=$ no pain score $2=$ Mild pain Score $3=$ Moderate pain Score 4=Severe pain 
Regarding bone density in laser group, there was a significant difference between different times of evaluation $(\mathrm{P}<0.001)$. Bone density analysis showed that Laser had significantly higher bone density after one month ,3 and 12 months compared to control group $(\mathrm{P}<=0.05)$. There was no significant difference in bone density between three month in control and one month in laser and between twelve month in control and three months in laser group.

\section{B) Area of the lesion}

\section{Overall comparisons of the two groups:}

Table 3. Figure 1, 2, 3

In control and laser groups, there are a square millimeter after one, three and twelve month comparing to area immediate after obturation. ( $\mathrm{p}$ $<0.05)$. Comparing the area values of control and laser groups, a significant difference was found throughout the three evaluation periods compared to the area immediate after obturation. There was a significant difference in the mean of area values between control and laser groups at one, three and twelve month, but there was no significant between three month in control and one month in laser and between twelve month in control and three months in laser group . significantly decrease in the area of the lesion in TABLE (2) Means \pm SD and statistical analysis of bone density in grey scale in control and laser group after different periods of obturation.

\begin{tabular}{|c|c|c|c|c|}
\hline Evaluation Periods & Group & Mean \pm SD & $P$ value & Significance \\
\hline \multirow[b]{2}{*}{ Immediate } & Control & $327.7 \pm 11.8^{\text {a }}$ & \multirow{2}{*}{$>0.5$} & \multirow{2}{*}{ N Sig } \\
\hline & Laser & $363.1 \pm 16.9^{a}$ & & \\
\hline \multirow[b]{2}{*}{ One month } & Control & $440 \pm 17.2^{\mathrm{b}}$ & \multirow{2}{*}{$<0.001$} & \multirow{2}{*}{ Sig } \\
\hline & Laser & $503.7 \pm 5.9^{\mathrm{c}}$ & & \\
\hline \multirow[b]{2}{*}{ Three months } & Control & $539.5 \pm 25.7^{\mathrm{c}}$ & \multirow{2}{*}{$<0.001$} & \multirow{2}{*}{ Sig } \\
\hline & Laser & $614.9 \pm 17.8^{\mathrm{d}}$ & & \\
\hline \multirow[b]{2}{*}{ Twelve month } & Control & $626.2 \pm 56^{d}$ & \multirow{2}{*}{$<0.001$} & \multirow{2}{*}{ Sig } \\
\hline & Laser & $741.2 \pm 12.45^{\mathrm{e}}$ & & \\
\hline
\end{tabular}

Different Small letters indicate significant difference $(p<0.05)$ by comparing bone density after different periods of obturation.

TABLE (3) Means \pm SD and statistical analysis of area of the periapical lesion in $\mathrm{mm}^{2}$ in control and laser group after different periods of obturation

\begin{tabular}{|c|c|c|c|c|}
\hline Evaluation Periods & Group & Mean \pm SD & P value & Significance \\
\hline \multirow{2}{*}{ Immediate } & Control & $27.7 \pm 1.8^{\mathrm{a}}$ & \multirow{2}{*}{$>0.5$} & \multirow{2}{*}{ N Sig } \\
\hline & Laser & $23.3 \pm 1.1^{\mathrm{a}}$ & & \\
\hline \multirow{2}{*}{ One month } & Control & $2 \underline{1+1.7^{\mathrm{b}}}$ & \multirow{2}{*}{$<0.001$} & \multirow{2}{*}{ Sig } \\
\hline & Laser & $16.33 \pm 2.3^{\mathrm{c}}$ & & \\
\hline \multirow{2}{*}{ Three months } & Control & $15.9 \pm 2.7^{c}$ & \multirow{2}{*}{$<0.001$} & \multirow{2}{*}{ Sig } \\
\hline & Laser & $11.03+1.7^{\mathrm{d}}$ & & \\
\hline \multirow{2}{*}{ Twelve month } & Control & $8.6 \pm 2.4^{\mathrm{e}}$ & \multirow{2}{*}{$<0.001$} & \multirow{2}{*}{ Sig } \\
\hline & Laser & $5.38 \pm 0.8^{\mathrm{f}}$ & & \\
\hline
\end{tabular}

Different Small letters indicate significant difference $(p<0.05)$ by area of the lesion after different periods of obturation. 


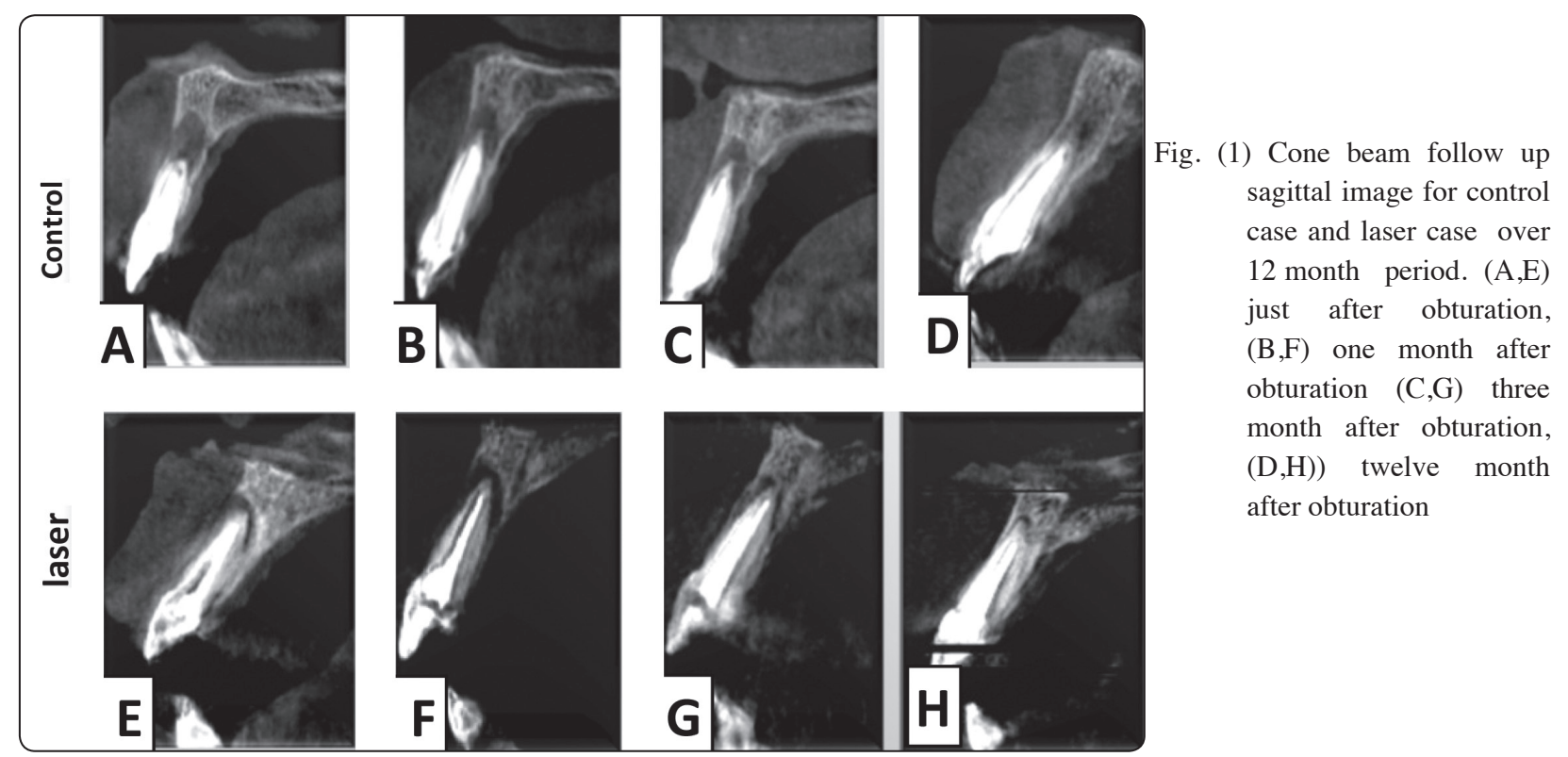

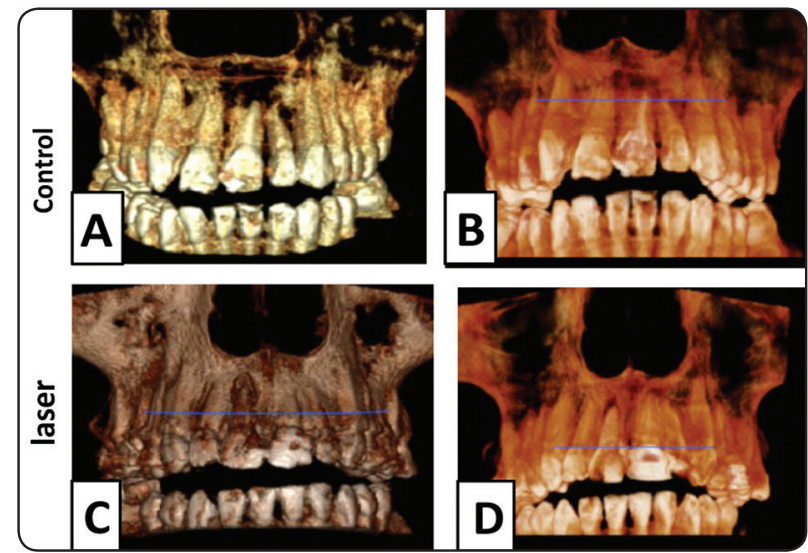

Fig. (2) Cone beam three-dimension image of the periapical lesion area in control and laser group .(A,C) just after obturation, (B,D) twelve month after obturation

\section{DISCUSSION}

This study was designed to asses, both clinically and radiographically, the healing effect of low level laser therapy on chronic apical lesions as clinical and radiologic criteria are frequently used to assess the status of endodontic treatment and its correlation with apical periodontitis ${ }^{(23-25)}$.

Periapical lesions of endodontic origin are produced by an inflammatory response at the root

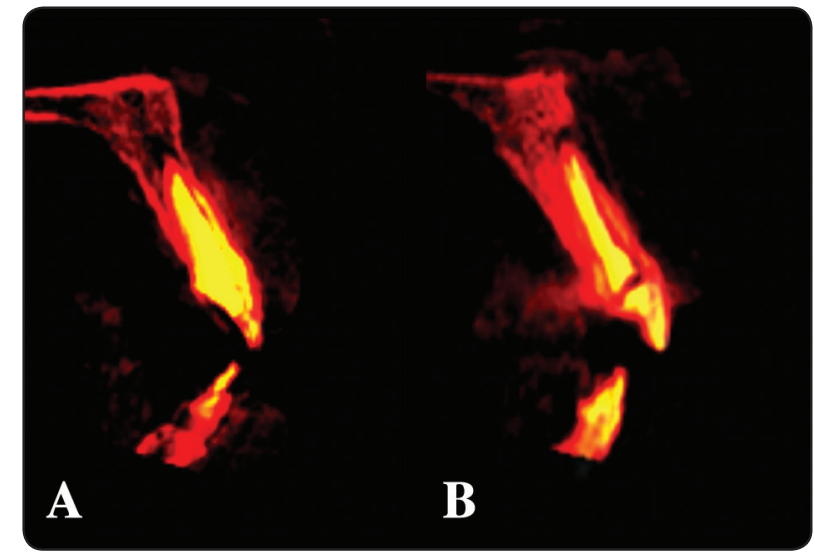

Fig. (3) Fused immediate after obturation and 12 months follows up sagittal image sections in control (A) and laser (B)

apices of teeth with non-vital pulps ${ }^{(26)}$. The first choice of treatment of periapical lesions should aim to eliminate microbial infection through treatment of the canals, in order to establish an environment favorable to healing ${ }^{(27)}$.

In reference to use the calcium hydroxide as intracanal medicament for one week in all cases of the present study, $\mathrm{Ca}(\mathrm{OH}) 2$ has antibacterial effect and can create an environment more conductive to healing and start bone repair ${ }^{(27)}$. This agrees 
with the findings of Sjogren et al ${ }^{(8)}$ and other authors who also reported that calcium hydroxide eliminates bacteria from the root canal and stimulate periapical healing through its antinflamatory effect of neutralizing acidic products and stimulation of alkaline phosphatase ${ }^{(28-30)}$.

Low -level lasers are thought to work by the interaction of light with the cell and tissue. This interaction might be affected by some parameters, such as wavelength, power, energy density, treatment duration, treatment intervention time, method of application, structure, and condition of the tissue ${ }^{(31)}$.

The $810 \mathrm{~nm}$ wavelength of the laser used for bone healing in the present study is within the infrared range and also within the so-called optical window that spans the red and near- infrared wavelengths; this wavelength ensures proper penetration of the laser light into biological tissues .Once light absorption and scattering (which is dependent on the wavelength and its maximal penetration) are obtained in a range between red and near-infrared lights, this interval will provide the ideal penetration into the biological tissue which in accordance with other study ${ }^{(32)}$.

In the present study LLLT was used with multiple low doses on multiple sessions (12 sessions), this provides a stimulatory effect at low doses and has been found to modulate various biological effects. Better biological effects were obtained by irradiation with multiple doses than single high dose. Application of LLLT has been very well recognized as an adjunctive approach in healing of periapical lesions ${ }^{(33,34)}$.

The clinical observation in this study showed faster healing of clinical symptoms associated with the periradicular lesions in lased group more than unlased one. These observations came in agreement with Alipanah et al (2011) ${ }^{(35)}$ who observed that LLLT with optimal parameters can accelerate full thickness wound healing. LLLT is successfully applied for tissue healing, mainly due to successful activation of the immune system, antioedematous effect and anti-inflammatory effect ${ }^{(36)}$. Further, a potential biostimulation of underlying and surrounding cells, increased collagen organization and promoting of growth factors and cytokines in response to laser irradiation have been demonstrated ${ }^{(18)}$.

In the present study, the degree of pain absence was faster in lased group as all patients recorded no pain by the fourth day, while in control group complete absence of pain was recorded by the sixth day. This came in agreement with previous studies that have shown the exposure of the gingiva over periapical area to low -level laser can reduce post -operative pain compared to control groups ${ }^{(37)}$.

To date, there are several suggested mechanisms for pain reduction following LLLT application, such as effect in modulating key factors of inflammation, reduction of the prostaglandin E2 level, inhibition of cyclooxygenase, and/or lymphocyte metabolism that could lead to reducing of edema, and further reduction of inflammatory processes ${ }^{(38,39)}$. Also, release of endogenous pain relievers - endorphins and enkephalins, the increase in production of serotonin and suppression of bradikinin activity ${ }^{(37,40)}$ has been suggested. It has been also shown that laser therapy increases systemic microcirculation by nitric oxide synthesis, causing the reduction in swelling and pain ${ }^{(37)}$. Even though, there are several potential mechanisms proposed, the real underlying mechanism following laser therapy for pain reduction is yet to be determined. It is believed that not just one, but two or more coexisting mechanisms or their combination are responsible for the beneficial outcome of LLLT in achieving analgesia.

Liang et al ${ }^{(41)}$ reported that the 3D CBCT has been found to be more sensitive than periapical radiographs in detecting periapical lesion treatment outcomes. Bone density values from CBCT might 
not correspond to values obtained with periapical radiographs. In the present study, the radiolucent area and bone tissue healing were evaluated by CBCT.

To standardize the study, all of the endodontic treatments and bone density values were performed and measured by the same researcher. A region of $2 \mathrm{~mm}^{2}$ was measured by using CBCT. The lowest bone density values were recorded in gray scale on scanning the periapical radiolucent area in the buccopalatal direction.

The findings of the present study revealed statistically significant differences between the control group and the laser-treated group at 1,3 and 12 month regarding bone density. However, no statistically significant differences were observed in the bone density between the control group at one month and the laser group at 3 months, also the control group at 3 month and laser group at 12 month. The findings of this study confirm the efficacy of LLLT in bone formation during healing of apical lesions and this may be due to its capacity in the differentiation of undifferentiated mesenchymal cells, osteoblasts ${ }^{(42)}$, osteosynthesis and reduction in osteoclastic activity and anti-inflammatory action (43), and due to the increase in vascularization ${ }^{(44)}$ or the capacity to increase the growth factors released in the periapical site ${ }^{(45,46)}$.

In the present study, as regard area of apical lesions, there was statistically significant differences between the control group and the laser-treated group at 1,3 and 12 month. To evaluate the healing of periapical lesions, Estrela et al ${ }^{(15)}$ successfully used $\mathrm{CBCT}$ and periapical index scoring to measure radiolucent areas. In the present study, instead of using an index to score bone density, bone density was quantitatively measured. With successful endodontic treatment, a decrease in the radiolucent area and bone tissue healing were observed. Both of these processes could be evaluated with CBCT.
It should be highlighted that there are no universally accepted parameters for the utilization of LLLT in bone healing in periapical lesion so an adequate clinical protocol might be reached in the future for bone regeneration in dentistry.

\section{CONCLUSIONS}

Based on the results of this study, it is possible to conclude that LLLT favored the bone healing process in apical lesions especially when combined with nonsurgical endodontic treatment.

Image fusion and CBCT can prove as an important tool for assessment of healing of periapical lesions after nonsurgical endodontic therapy. It is an effective method for evaluating bone density in endodontic treatment so it is a useful tool for observing the bone accumulation in periapical lesions, but there is a need to reduce the radiation dosage.

\section{REFERENCES}

1. Kaya S, Yauuz I, Uysal I, and Akkus Z. Measuring bone density in healing periapical lesions by using cone beam computed tomography:A clinical investigation.J Endod 2012;38:28-31.

2. Figdor D. Apical periodontitis: a very prevalent problem. Oral Surg Oral Med Oral Pathol Oral Radiol Endod 2002;94:651-2.

3. Metzger Z. Macrophages in periapical lesions. Endod Dental Traumatol 2000; 16:1-8.

4. Rocas IN, Siqueira JF Jr. Characterization of microbiota of root canal-treated teeth with posttreatment disease. J Clin Microbiol 2012: 50: 1721-1724.

5. Katebzadeh N, Sigurdsson A, Trope M. Radiographic evaluation of periapical healing after obturation of infected root canals : an in vivo study.Int Endod J 2000,33,60-66.

6. Kim D and Kim E .Antimicrobial effect of calcium hydroxide as an intracanal medicament in root canal treatment : a literature review- Part II. In vivo studies . Restor Dent Endod. 2014 ;39(4):241-52

7. Kusgoz AK, Yildirim S, Gokalp A. Nonsurgical endodontic treatments in molar teeth with large periapical lesions 
in children: 2-year follow-up. Oral Surg Oral Med Oral Pathol Oral Radiol Endod. 2007;10(104):60-5.

8. Sjogren U, Figdor D, Spangberg L,Sundqvist G .The antimicrobial effect of calcium hydroxide as a short -term intracanal dressing .Int Endod J 1991;24 (3) : 119-25.

9. Peters C \& Peters O. Cone beam computed tomography and other imaging techniques in the determination of periapical healing. Endodontic Topics 2012, 26, 57-75

10. Vandenberghe B, Jacobs R, Bosmans H. Modern dental imaging: a review of the current technology and clinical applications in dental practice. Eur Radiol 2010: 20: 26372655.

11. Cotton TP, Geisler TM, Holden DT, Schwartz SA, Schindler WG. Endodontic applications of cone-beam volumetric tomography. J Endod 2007: 33: 1121-1132.

12.. Nair MK, Nair UP. Digital and advanced imaging in endodontics: a review. J Endod 2007: 33: 1-6.

13. Patel S, Dawood A. The use of cone beam computed tomography in the management of external cervical resorption lesions. Int Endod J 2007: 40: 730- 737.

14. Arai Y, Tammisalo E, Iwai K, Hashimoto K, Shinoda K. Development of a compact computed tomographic apparatus for dental use. Dent Maxillofac Radiol 1999; 28:245-8.

15. Estrela C, Bueno MR, Azevedo BC, Azevedo JR, Pecora JD. A new periapical index based on cone beam computed tomography. J Endod 2008;34:1325-31.

16. Patel S, Dawood A, Pitt Ford T, Whaites E. The potential applications of cone beam computed tomography in the management of endodontic problems. Int Endod $\mathrm{J}$ 2007;40:818-23.

17. Siddharth M,Kaur S.Low level laser therapy aas an adjunct to non surgical periodontal treatment in patients with chronic periodontitis -A review. J Res Adv Dent 2014; 3 :82-86.

18. Asnaashari M, Safavi N. Application of low level lasers in dentistry. J Lasers Med Sci 2013 ;4:57-66.

19. Aykel G, Basser U ,Maden I et al . The effect of low level laser therapy as an adjunct to non surgical periodontal treatment .J periodont $2011 ; 82: 481-488$.

20. Parker S. Low level laser use in dentistry. British Dent J 2007; 202: 131-138.
21. Da Cunha SS, Sarmento V, Ramalho LM, De Almeida D, Veeck EB, Da Costa NP, Mattos A, Marques AM, Gerbi M, Freitas AC .Effect of laser therapy on bone tissue submitted to radiotherapy: experimental study in rats. Photomed Laser Surg 2007. 25:197-204

22- Negm M.M . Effect of intracanal use of nonsteroidal antiinflammatory agents on post treatment endodontic pain .J Oral Surg Oral Med Oral Path.1994;77(5): 507-13.

23. Simon JHS, Enciso R, Malfaz JM, Rogers R, Bailey-Perry M, Patel A. Differential diagnosis of large periapical lesions using cone beam computed tomography measurements and biopsy. J Endod 2006; 32:833-7.

24. Velvart P, Hecker H, Tillinger G. Detection of the apical lesion and the mandibular canal in conventional radiography and computed tomography. Oral Surg Oral Med Oral Pathol Oral Radiol Endod 2001; 92: 682-8.

25. 1-Venugopal P., Anil Kumar.S, Jyothi.K.N. Successful healing of periapical lesions With non-surgical endodontic approach. Journal of Dental Sciences \& Research 2011; 2(1) : $1-6$.

26. Saatchi M. Healing of large periapical lesion: a non surgical endodontic treatment approach .Aust Endod J 2007; 33(3) : 136-40.

27. Tsurumachi T, Suguro H, Ogata H, Hatori K, Kobayashi C, Ogiso B. Endodontic treatment of bilateral dens evaginatus premolars with large periapical lesions.J Oral Sci 2009; 51 (3) : 475-9.

28. Farhad A, Mohammadi Z. Calcium hydroxide: a review. Int Dent J 2005; 55:293-301.

29. Masoud Saatchi.Healing of large periapical lesion: A non surgical treatment approach. Aust Endod J 2007; 33: $136-140$.

30. Aykol G, Baser U,Maden I,Kazak Z Kucuk S,Onan U, Tanrikulu-Kucuk S, Ademoglu E,Yalcin F. The effect of low- level laser therapy as an adjunct to non-surgical periodontal treatment. J Periodontal 2011; 82:481-488.

31. Regina V, Selta G Costa do Bomfim F, Effect of low-level laser therapy on bone repair:a randomized controlled experimental study.Lasers Med Sci 2015; January : 17101716.

32. Kazem Shakouri S, Soleimanpour J, Salekzamani Y and Oskuie MR: Effect of low-level laser therapy on the fracture healing process. Lasers Med Sci 25: 73-77, 2010. 
33. Ninomiya T, Hosoya A, Nakamura H, Sano K, Nishisaka $\mathrm{T}$ and Ozawa $\mathrm{H}$ : Increase of bone volume by a nanosecond pulsed laser irradiation is caused by a decreased osteoclast number and an activated osteoblasts. Bone 2007; 40: 140-148, .

34. Alipanah Y, Asnaashari M, Anbari F. The effect of low level laser (GaAlAs) therapy on the post-surgical healing of full thickness wounds in rabbits. Med Laser Application. 2011; 26(3): 133-8.

35. de Lima Mafra F, Costa MS, Albertini R, Silva JA, Aimbire F. Low level laser therapy (LLLT): Atenuation of cholinergic hyperre-activity, beta(2)-adrenergic hyporesponsiveness and TNF-alpha mRNA expression in rat bronchi segments in E. coli lipopolysaccharide-induced airway inflammation by a NF-kappaB dependent mechanism. Lasers Surg Med 2009; 41(1): 68-74.

36. Kreisler MB, Haj HA, Noroozi N, Willershausen B, Bd'Hoedt. Efficacy of low level laser therapy in reducing postoperative pain after endodontic surgery- a randomized double blind clinical study. Int J Oral MaxilofacialSurg 2004; 33(1):38-41.

37. Nascimento S. B, Cardoso ., C.A., Ribeiro T.P. et al. "Effect of low-level laser therapy and calcitonin on bone repair in castrated rats: a densitometric study," Photomedicine and Laser Surgery 2010 ; 28: 45-49.

38 Asnaashari M, Mohebi S, Paymanpour P. Pain reduction using low level laser irradiation in single-visit endodontic treatment. J Lasers Med Sci. 2011; 2(4):139-43.

39. Zand N, Ataie-Fashtami L, Djavid GE, Fateh M, Alinaghizadeh M, Fatemi S, et al. Relieving pain in minor aphthous stomatitis by a single session of non-thermal carbon dioxide laser irradiation. Lasers Med Sci 2009; 24(4): 515-20.

40. Liang YH, Li G, Wesselink PR, Wu MK. Endodontic outcome predictors identified with periapical radiographs and cone-beam computed tomography scans. J Endod 2011;37:326-31.

41. Khadra, M., Haanaes, H.R., Ellingsen, J.E. \& Lyngstadaas, S.P. Enhancement of bone formation in rat calvarial bone defect using low level laser therapy. Oral Surgery, Oral Medicine, Oral Pathology, Oral Radiology, and Endodontology 2004; 97: 693-700.

42. Stein, A., Benayahu, D., Maltz, L. \& Oron, U..Low-level laser irradiation promotes proliferation and differentiation of human osteoblasts in vitro. Photomedicine and Laser Surgery 2005; 23: 161-166.

43. Maegawa, Y., Itoh, T., Hosokawa, T., Yaegashi, K. \& Nishi, M. .Effects of near-infrared lowlevel laser irradiation on microcirculation. Lasers in Surgery and Medicine 2000; 27: 427-437.

44. Saygun, I., Karacay, S. \& Serdar, M. Effects of laser irradiation on the release of basic fibroblast growth factor (bFGF), insulin like growth factor-1 (IGF-1), and receptor of IGF-1 (IGFBP3) from gingival fibroblasts. Lasers in Medical Science 2008; 23: 211-215.

45. Damante, C.A., de Micheli, G., Miyagi, S.P.H., Feist, I.S \& Marques, M.M. Effect of laser phototherapy on the release of fibroblast growth factors by human gingival fibroblasts. Lasers in Medical Science 2009 ; 24, 885-891 